\title{
"Eu não faço nada que seja do sexo contrário": Narrativas de adolescente sobre as construções do masculino
}

\author{
"No hago nada que sea del sexo contrario ":Narrativa de adolescentes sobre las \\ construcciónes del masculino
}

\author{
"I do nothing that is from the opposite sex": teenagers' narratives about the \\ constructions of the male
}

\author{
Marcia de Bastos Braatz \\ Universidade de Santa Cruz do Sul (UNISC), Santa Cruz do Sul - RS/Brasil \\ ORCID: 0000-0002-8109-4664 \\ E-mail: m.braatz.psi@gmail.com
}

Gabrielly da Fontoura Winter

Universidade de Santa Cruz do Sul (UNISC), Santa Cruz do Sul - RS/Brasil ORCID: 0000-0003-2981-0640

E-mail: gabywinter@hotmail.com

\section{Resumo}

Este estudo tem por objetivo analisar as concepções de adolescentes do sexo masculino acerca da masculinidade. Para dar materialidade a pesquisa foram realizadas entrevistas semiestruturadas com 3 adolescentes em cumprimento de medidas socioeducativas (MSE) em um município do interior do Rio Grande do Sul, sendo analisadas conforme propõe Mary Jane Spink (2010), acerca da produção de sentidos. Temática que toma relevância frente aos altos índices em relação aos atos infracionais cometidos por adolescentes do sexo masculino, totalizando cerca de $96 \%$ no cumprimento de MSE em âmbito fechado e, cerca de $88 \%$ na modalidade aberta. Esta realidade suscita reflexões sobre o fenômeno do ato infracional e a construção do gênero masculino. Através dos resultados desta pesquisa pode-se perceber que o processo de construção da identidade e as relações de gênero costuram-se na trama social de tal modo que as narrativas apresentadas pelos adolescentes em cumprimento de MSE corroboram com o que a literatura apresenta sobre a adolescência em geral, possibilitando assim novos olhares acerca da temática do jovem em conflito com a lei.
\end{abstract}

Palavras-chaves: Adolescência; Masculinidade; Gênero; Ato infracional.

\begin{abstract}
Resumen
Este estudio tiene como objetivo analizar las concepciones de los adolescentes varones sobre la masculinidad. Para dar materialidad a la investigación, se realizaron entrevistas semiestructuradas con 3 adolescentes en cumplimiento de medidas socioeducativas (MSE) en un municipio del interior de Rio Grande do Sul, siendo analizadas conforme lo propuesto por Mary Jane Spink (2010), sobre la producción de significados, cobra relevancia ante los altos índices en relación a las infracciones cometidas por los adolescentes varones, totalizando alrededor del $96 \%$ en el cumplimiento de la AMP en ambiente cerrado y, alrededor del $88 \%$ en la modalidad abierta. Esta realidad suscita reflexiones sobre el fenómeno de la infracción y la construcción del género masculino. A través de los
\end{abstract}

resultados de esta investigación se puede apreciar que los procesos de construcción identitaria y las relaciones de género se cosen en el tejido social de tal manera que las narrativas presentadas por los adolescentes en el cumplimiento de la MSE corroboran lo que la literatura presenta sobre la adolescencia en general, posibilitando así nuevas perspectivas sobre el tema de los jóvenes en conflicto con la ley.

Palabras clave: Adolescencia; Masculinidad; Género; Acto infractor.

Abstract
This study aims to analyze the conceptions of male
adolescents about masculinity. To give materiality to the
research, semi-structured interviews were carried out 
with 3 adolescents in compliance with socio-educational measures (MSE) in a city in the Rio Grande do Sul, being analyzed as proposed by Mary Jane Spink (2010), about the production of meanings. Theme that becomes relevant in view of the high rates of infractions committed by male adolescents, totaling about $96 \%$ in the fulfillment of MSE in a closed scope and, about $88 \%$ in the open modality. This reality raises reflections on the phenomenon of the infraction and the construction of the masculine gender. Through the results of this research, it can be seen that the process of identity construction and gender relations are sewn into the social fabric in such a way that the narratives presented by adolescents in compliance with MSE corroborate what the literature presents about adolescence. in general, thus enabling new perspectives on the issue of young people in conflict with the law.

Keywords: Adolescence; Masculinity; Gender; Infractional act.

\section{Introdução}

Tanto os homens, quanto as mulheres, são chamados e preparados desde o nascimento para assumir papéis estabelecidos socialmente (Vasconcelos, Monteiro, Facundes, Trajano \& Gontijo, 2016). Este processo dá-se de maneira gradual e passa por uma fase de validação diretamente ligada à adolescência; pautada por diversas transformações nas esferas fisiológica/anatômica, psicológica e social. O adolescente constrói a sua identidade descobrindo e vivenciando o que é ser e sentirse adolescente, além de deparar-se com diversas novas experiências em relação à sexualidade. Neste sentido, Domingues e Alvarenga (1997) consideram a adolescência uma fase importante da vida, possibilitando o processo de identificação de gênero, assim como a sexualidade "apresenta-se como elemento importante na formação da identidade adolescente, manifestada através de múltiplas identificações características, como a da imagem corporal, a da identificação com o masculino e/ou feminino" (Domingues \& Alvarenga, 1997, p. 38).

Segundo Connell e Messerschmidt (2013), existem modelos de masculinidades que se consolidam com maior legitimidade social, assumindo características hegemônicas e reguladoras de atitudes e comportamentos. A fase da adolescência assume um papel de experimentação e exercício das vivências legitimadoras da sua identidade. A concepção de "homem" no sentido "viril" e "másculo" vem sendo perpetuada ao longo dos anos, principalmente no cerne familiar, que por sua vez é atravessado pelas concepções sociais e culturais de sua época. Há um esforço familiar e cultural para que haja um distanciamento por parte dos meninos da figura feminina (também construída socialmente) (Boris, Bloc \& Teófilo, 2012). Assim, desde a infância, são orientados para que se portem "como homens", "não chorem como mulherzinha", "não expressem seus sentimentos, angustias e aflições". Aspectos esses, que serão privilegiados ao longo das discussões que seguem mais adiante.

A temática deste estudo busca privilegiar reflexões acerca dos atravessamentos sociais que compõem os processos de construção das identidades masculinas e suas relações com o ato infracional. De acordo com levantamentos realizados por órgãos públicos como a Fundação de Assistência Socioeducativa do Estado do Rio Grande do Sul (FASE), Sistema Nacional de Atendimento Socioeducativo (SINASE) e Conselho Nacional de Justiça (CNJ) nos últimos anos, evidencia-se uma característica peculiar em relação ao ato infracional e o cumprimento das medidas socioeducativas; em sua maioria, independentemente da modalidade ou unidades da federação, o cenário é o mesmo: o número de adolescentes do sexo masculino em cumprimento destas é disparadamente maior do que para o sexo feminino.

É neste cenário, que surge a necessidade de compreender como se dão os processos de construção da identidade masculina e de que forma o gênero masculino passa a ocupar o protagonismo do ato infracional. Os fatores históricos, sociais e culturais influenciam diretamente neste processo de identificação, sendo possível apenas compreender o sujeito e seu gênero, levando em conta os 
atravessamentos que compõem a sua realidade. Historicamente a masculinidade é vivenciada e validada na trama social a partir de atitudes, modos de ser e existir específicos, marcados pela diferenciação ao sexo feminino; sendo assim, o masculino deve portar-se, sentir-se e apresentar-se a partir dos pressupostos históricos e sociais atribuídos a esse gênero, tendo os traços da virilidade, força e coragem como algo inato ao masculino (Silva, 2000).

Segundo dados expostos pelo levantamento anual do Sistema Nacional de Atendimento Socioeducativo - SINASE (2018), cerca de $96 \%$ dos adolescentes em cumprimento de medida socioeducativa, na modalidade de internação ou semiliberdade, no Brasil são do sexo masculino. No Rio Grande do Sul, ainda segundo o mesmo órgão, esta realidade passa a representar cerca de $97 \%$ da população em cumprimento de medidas. Para as medidas em meio aberto, conforme divulgado recentemente pelo Ministério do Desenvolvimento Social, através da Rede SUAS (2018), cerca de $88 \%$ da população em cumprimento de medida socioeducativa é do sexo masculino. As distintas características que compõem esse arranjo social assumem protagonismo na grande incógnita que se instaura a partir das estatísticas. Desta forma, faz-se necessário buscar compreender este fenômeno, uma vez que analisar esta problemática pode auxiliar a criar ferramentas de mudança que vão muito além da responsabilização e reinserção, mas possibilita refletir sobre a estrutura social.

Neste sentido, este estudo buscará compreender a linha tênue que evidencia o fenômeno entre o gênero e o conflito com a lei. A fim de suscitar uma reflexão acerca deste fenômeno, que não é novo, mas requer novos olhares sobre a questão da identidade masculina e como a sociedade vem subjetivando e criando formas de validação e/ou exclusão social diretamente ligadas ao gênero.

\section{Metodologia}

Esta pesquisa surgiu da relevância socio-cultural que a compreensão acerca dos fenômenos que corroboram na construção da identidade de gênero tem, de forma a elucidar seus atravessamentos e reverberações sociais, aqui alocadas no recorte do elevado número de adolescentes do sexo masculino em cumprimento de medida socioeducativa no país, conforme citado anteriormente. Através de uma postura ética no pesquisar, faz-se importante lembrar que Deleuze (2013) nos alerta sobre a indignidade de falar pelos outros, pois o conhecimento científico é um recorte que nos diz sobre nós, enquanto pesquisadores, e dos outros, portanto da nossa própria competência e situação. Desta forma, esta pesquisa é situada, escrita por mulheres, psicólogas, brancas, heterossexuais, portanto socializadas dessas maneiras, impulsionadas a pensar sobre os regimes de possibilidades que constroem a masculinidade e as possíveis relações com os atos infracionais.

Para a realização deste estudo elegeu-se a Hermenêutica Fenomenológica como metodologia. Esta, "permite-nos vivenciar pela interpretação os significados a partir do diálogo com o mundo" (Silva, 2010, p. 55), contemplando o conhecimento como "dependente da compreensão subjetiva ou intersubjetiva dos fenômenos em suas diversas manifestações e contextos. E somente o sujeito pode compreender o fenômeno através do contexto histórico no qual ocorre" (Silva, 2010, p. 58). De acordo com Melo (2016, p. 301) "a pesquisa qualitativa de orientação fenomenológica no campo da psicologia requer necessariamente que a experiência e o comportamento investigados sejam expressos na forma de discurso". Desta forma, buscou-se compreender a partir dos jovens que vivenciam este processo fenomenológico, com suas percepções, atravessamentos e construções, como protagonistas deste cenário, privilegiando seus saberes acerca do próprio processo constitutivo.

Para tanto, foram realizadas entrevistas semiestruturadas, com 3 adolescentes em 
cumprimento de medida socioeducativa em um município do interior do Rio Grande do Sul, no ano de 2018. As entrevistas foram realizadas em parceria com o Centro de Referência Especializado de Assistência Social-CREAS, que além de ceder o espaço físico adequado, respeitando a privacidade e o sigilo, auxiliou na aproximação aos adolescentes. Inicialmente, pensou-se em construir este estudo com 5 adolescentes inseridos neste contexto, porém, dada a sensibilidade que a formação de vínculos possui, bem como a implicações de tempo, optou-se por prosseguir com os 3 adolescentes dispostos a participar da pesquisa.

Buscou-se identificar a partir de suas narrativas, as concepções em relação à masculinidade, suas características e percepções, sendo assim, o recorte constitutivo das entrevistas delimitou-se a estes, não tendo sido abordado, nesta oportunidade, questões acerca de suas percepções sobre atos infracionais. As entrevistas foram audiogravadas e posteriormente transcritas, de modo sequencial, conforme propõe Mary Jane Spink, a fim de visualizar e sublinhar os significados, as posições, referências e os sentidos que permeiam os discursos dos sujeitos/atores participantes (Spink, 2010). A partir deste momento, os entrevistados responderão por pseudônimos. Esses foram escolhidos a partir de suas concepções semânticas sendo eles: André (que significa "másculo", "virill", "masculino". Tem origem no grego Andreas, com origem no termo 'andrós'= homem); Bernardo (que significa "forte como um urso") e Heitor (é um nome de origem grega (Héktor) que significa "o que aguenta", no sentido de tenacidade. $\mathrm{Na}$ mitologia, era o nome de um grande guerreiro na Guerra de Troia, sendo um dos heróis da Ilíada, de Homero).

Observou-se as Resoluções 466/2012 e 510/2016 do Conselho Nacional de Saúde. Obteve parecer favorável do Comitê de Ética em Pesquisa da Universidade de Santa Cruz do Sul-UNISC, registrado sob CAAE: 91514718.9.0000.5343. Todos os adolescentes, bem como seus responsáveis, assinaram os
Termos de Consentimento Livre e Esclarecido e Assentimento Livre e Esclarecido.

\section{A construção da identidade masculina e a diferenciação com o outro}

A maneira como o sujeito se reconhece e reconhece o outro passa por um processo não apenas subjetivo de identificação, mas que também se constrói na trama social e valida-se ao longo do tempo e espaço em que o fenômeno ocorre. Neste sentido, de acordo com Zambrano e Heilborn (2012, p. 412), a identidade de gênero se refere a forma como o sujeito "se percebe e é percebido pelos outros como masculino ou como feminino, de acordo com os significados que esses termos têm na cultura a que pertencem".

É neste cenário que passemos a pensar como se dão os processos de validação e significação das práticas e construção da identidade. As experiências e representações construídas a partir dos fenômenos culturais passam a sinalizar as formas como os sujeitos se identificam em sociedade. Para Woodward (2012) a representação estabelece tanto identidades individuais, quanto coletivas; assim, os sistemas de representações possibilitam aos sujeitos a construção de lugares de pertencimento, fala e posicionamento. "É por meio dos significados produzidos pelas representações que damos sentido às experiências e àquilo que somos." (Woodward, 2012, p. 218).

As formas de se colocar, ser e existir em diferentes contextos e situações referem-se às experiências obtidas desde o nascimento e mantem-se em constante atualização com o passar dos anos, na medida das novas vivências. Este processo, constituinte dos sujeitos, é resultado de diversos recursos sociais utilizados no exercício de poder e normalização social que, conforme Boris, Bloc e Teófilo (2012), apresenta-se por meio de mecanismos de inclusão e exclusão. Assim, podemos perceber o quão importante é o papel exercido pelo meio social no processo de construção da identidade. Ademais, buscar compreender como se construiu e ainda se 
constrói a masculinidade envolve compreender o momento social e histórico de cada sociedade, bem como suas demandas.

Para Silva (2012) a identidade se constrói através do reconhecimento da diferença, e esta, por sua vez, também só se constitui a partir da identidade, em uma relação de retroalimentação. É nesta dinâmica de identificação, reconhecimento e pertencimento que a identidade dos sujeitos se compila. As práticas, características e formas de ser e existir vão sendo forjadas nessa esfera cultural. Ao passo em que ocorre a normalização das condutas e características, tanto a identidade, quanto a diferença se constroem. Assim, "identidade e diferença são, pois, inseparáveis" (Silva, 2012, p. 75).

Para tanto, este estudo traça um caminho pelo qual buscamos compreender os sentidos e significados que os adolescentes atribuem à masculinidade. De forma paralela, os conceitos de identidade e diferença nortearão as reflexões descritas a seguir, visto que este é um fenômeno evidente nas narrativas dos sujeitos entrevistados, tendo em vista que o processo de construção da própria identidade, também passa pela diferenciação em relação ao outro.

\section{Um não é o outro pelo critério da exclusão: o binarismo de gênero}

Em diversos momentos as sociedades buscaram diferenciar sua população, iniciando pelas diferenças físicas, a exemplo a sociedade Pré-Vitoriana. Nesta, concebia-se a mulher como um "homem inferior", comparando sua genitália e aparelho reprodutor ao do homem, seguindo o pressuposto de superioridade masculina diretamente ligada à genitália em apêndice, bem formada e evoluída, enquanto a feminina se tratava de algo incompleto (Silva, 2000).

Segundo Martins (2004), anteriormente à construção da ciência biológica, as diferenças em relação ao corpo humano pautavam-se em concepções cósmicas e hierárquicas. Em que o modelo do sexo único (homologias sexuais), cujo as origens estão nos escritos de Aristóteles e Galeno, foram predominantes até a Revolução Científica do Século XVII (Laqueur, 1992 apud Martins, 2004). Para Galeno o corpo humano expressava uma "ordem natural e hierárquica que organizava o cosmos e o mundo dos seres vivos" (Martins, 2004, p. 27), baseavam-se, ainda, no princípio do calor vital, sendo os seres quentes mais perfeitos. Assim, a mulher considerada úmida e fria estava hierarquicamente abaixo do homem, que tinha uma natureza seca e quente. Deste modo, a figura construída do homem passa a ser sinônimo de perfeição, medida e padrão para todos os seres vivos. À mulher restou a comparação e a conotação de imperfeição, justificada pela ausência de calor suficiente para exteriorização dos seus órgãos sexuais (Martins, 2004).

Com o advento da nova ciência biológica, os homens do século XVIII, passam a dar grande enfoque às diferenças, suas descobertas e observações pautavam-se na diferenciação e catalogação destas. Para onde quer que olhassem, avolumavam-se as diferenças, sejam entre os minerais, plantas, animais ou seres humanos. As evidências de diferenciação dos sexos, considerando o tamanho do crânio, estrutura óssea e alargamento do quadril, ressaltavam a concepção de fragilidade e inferioridade feminina. O que passa a fortalecer, ainda mais, a convicção de que a forma corresponde à função, algo que ao ser ressignificado socialmente passa a ter relação determinante entre o corpo e os papéis sociais desempenhados (Martins, 2004).

Ao final do século XVIII e ao longo do século XIX, a concepção em relação a identidade de gênero dos sujeitos estava diretamente ligada ao sexo biológico; período este em que surge o conceito "Two Sex Model", que se refere a apenas dois modelos de sexo possível (homem $\mathrm{x}$ mulher) ou sexualidade (homossexual $\mathrm{x}$ heterossexual), o que por muitos anos ao longo da história não apenas serviu para a caracterização da masculinidade, mas também para diferenciação entre homens e mulheres (Silva, 2000). 
É percebido até o momento como os processos de construção da identidade masculina perpassam por um importante percurso sociocultural diretamente ligado à observação física, palpável e concreta das diferenças. Posto isso, é a partir destes fatores que podemos evidenciar o primeiro aspecto apontado pelos adolescentes como sendo constituinte da identidade masculina. Ao reportarem as características do ser masculino, todos os adolescentes iniciam suas falas a partir da diferenciação, e esta, por sua vez, é uma diferenciação calcada em uma esfera binária que anuncia, não apenas as diferenças, mas também as oposições.

O sexo, o sexo... O homem é diferente de mulher, né...Para mim é só para diferenciar o que é homem e mulher... o homem tem pênis e a mulher tem vagina. (André)

As partes intimas... O pé maior do que $o$ da mulher. Seria mais alto... (Bernardo)

A voz mais grossa.... Ele não tem peito (Heitor)

A unanimidade das primeiras narrativas em relação à diferenciação ao feminino evidencia os atravessamentos na cultura, tempo e espaço que as concepções em relação ao feminino e masculino alcançam. É evidente o quanto o fator biológico se apresenta não apenas na historicidade como um importante marcador, mas também no contemporâneo, assumindo o início da diferenciação e, assim, da identidade. Como Silva (2000) pontua, ao longo da história ser homem significava não ser mulher, fator também sinalizado pelos adolescentes entrevistados.

Estas características descritíveis, visíveis e palpáveis, estão impostas ao sujeito desde o nascimento, ou até mesmo antes, através da designação sexual. Para Woodward (2012, p. 15) “o corpo é um dos locais envolvidos no estabelecimento das fronteiras que definem quem nós somos, servindo de fundamento para a identidade - por exemplo, para a identidade sexual". O que novamente retorna à discussão em relação a identidade e diferença produzidas pela cultura; visto que é ela quem vai definir as características que incluem ou excluem, o que é importante e o que é irrelevante para o processo de identificação (Woodward, 2012).

É nesta trama sociocultural que as relações vão sendo vivenciadas e adquirem status de importância nos processos de construção da identidade. Assim, não apenas o visível, palpável e mensurável é protagonista nesta dinâmica, há espaço para outro ator que se insere: o comportamento. A necessidade de diferenciação e distanciamento em relação ao feminino, como coloca Silva (2000), caracteriza a masculinidade há séculos. E ainda hoje, a figura masculina que seja associada à feminilidade pode ser concebida como decadente, um comportamento que deve ser podado.

Com o início do século XIX e entrada na Era Vitoriana, com as obras de arte retratando o homem de sua época, prevalecia a ideia de que o ser homem, neste momento histórico, estava marcado pelo fato de não ser mulher. Esta concepção ainda hoje faz-se presente nos discursos sociais, porém tal colocação remete-se ainda a atribuições que foram dadas às mulheres e excluídas aos homens (Silva, 2000).

Os traços que os descreviam, voltavam-se para a forma de se vestir, a forma de andar, a maneira de se comportar, a entonação de voz, etc., assim como também era ressaltado a forma física, a musculatura, os contornos do corpo masculino, a elegância, o vigor físico e a beleza, e por fim, as qualidades psicológicas do homem como a agilidade, a coragem, a distinção, a bravura, o heroísmo. A sociedade masculinista burguesa, dado essa premissa, construía, assim, a nova imagem de homem, e como consequência vieram as duras provas pelas quais o homem deveria enfrentar, como as lutas, como um dos 
componentes do comportamento masculino (Silva, 2000, p. 11).

Neste sentido, se à figura feminina foram dados atributos consideráveis "frágeis", aos homens, a partir do pressuposto de oposição, elencou-se a virilidade e força como características (Boris et al, 2012). Ao encontro disso, Pongeluppe e Milani (2017) reiteram o esforço exercido pela figura masculina em provar-se não ser mulher, não ser homossexual e não ser feminino. A partir do mesmo entendimento, Betim e Lurke (2019) sinalizam que a repressão sofrida pelos homens quanto sua identidade é vivenciada desde a infância, relacionando-se com os altos índices de violência que protagonizam, gerando a necessidade deturpada de afirmar estar no lugar socialmente "correto". Além dos fatores anátomo-fisiológicos, as características comportamentais evidenciaram as formas de ser e existir da masculinidade. Ao passo que a identidade não se constrói apenas pelo visível, mas se dá também nas interações e relações ocorridas no cotidiano. Podemos evidenciar, a partir das falas dos Participantes:

Acho que o homem é mais soltão, né, do que a mulher. A mulher é mais tímida, mais delicadinha. O homem eu acho que já não é! ... Soltão de fazer as coisas... sei lá, se tiver que apontar, se tiver que fala, fala. A mulher já é mais toda atenciosa. Sei lá, fica pra ela as coisas. O homem já é mais explosivo. (André)

Ah, como é que se diz, assim... Brabo, assim.... rígido... Não tem tanto sentimento, assim. Não sei... Não demonstram. Porque todo homem tem sentimentos. (Heitor).

Souza (2005) traz que mesmo com grandes mudanças em relação à atribuição de novos sentidos a masculinidade, ainda hoje se tem uma forte ligação com padrões cultivados por séculos. E este fenômeno pode ser evidenciado pelas falas dos adolescentes relacionadas ao comportamento visto como genuinamente masculino. A Rigidez, a impulsividade e o distanciamento à delicadeza -dita feminina- apresentam-se como características cultivadas ao longo da história e validadas nos acontecimentos cotidianos. Exemplo de como a questão da diferença e identidade perpassa pelas múltiplas esferas da vida do sujeito. Assim, os atravessamentos que compõem a construção e propagação do ideal masculino se dá nesta dinâmica entre sujeito, sociedade e cultura.

\section{Masculinidade e pertencimento: as formas de se constituir a partir do social}

As formas como os adolescentes narram suas percepções, referências e significados sobre a masculinidade, permite-nos perceber como se dão os processos de construção da identidade de gênero. Esta, por sua vez, deve ser distinguida da ideia de sexo biológico, ainda que haja uma frequente associação tratam-se de fenômenos, não excludentes, mas sim diferentes. A identidade sexual se constrói conforme a sexualidade é vivenciada por cada sujeito. Já a identidade de gênero, perpassa um processo de identificação (Louro, 1997).

Para Weeks (1993, p. 6, apud Louro, 1997) "a sexualidade tem tanto a ver com as palavras, as imagens, o ritual e a fantasia como com o corpo", sendo impossível compreendê-la dissociada também de seus aspectos inconscientes e culturais, privilegiando apenas os fatores anátomo-fisiológicos. Assim, para compreender a dinâmica entre o gênero e a sexualidade, é preciso compreender que esta, apesar de seu caráter biológico, não é dada, não existe a priori. Portanto, a sexualidade também passa pelo processo de significação cultural e construção social.

Para Butler (2003) existe uma construção de ordem imperativa que exige dos sujeitos de nossa sociedade práticas coerentes entre gênero e sexo, de caráter estritamente heterossexual. Assim, o gênero se constitui nas relações sociais, baseado nas diferenças percebidas a partir do biológico, apresentandose como campo primeiro, no qual as relações de poder vão se articular (Silva \& Silva, 2016). 
Butler (2003) coloca em questão as concepções acerca do determinismo em relação ao sexo e aos atributos biológicos, que subjetivam e justificam as produções de verdade em relação ao gênero. Não de forma a refutar as construções históricas e culturais descritas até o momento, mas como uma forma diferente de olhar o fenômeno do sexo e a identidade de gênero.

Se o caráter imutável do sexo é contestável, talvez o próprio construto chamado "sexo" seja tão culturalmente construído quanto o gênero; a rigor, talvez o sexo sempre tenha sido o gênero, de tal forma que a distinção entre sexo e gênero se revela absolutamente nenhuma. Se o sexo é, ele próprio, uma categoria tomada em seu gênero, não faz sentido definir o gênero como uma interpretação cultural do sexo. $\mathrm{O}$ gênero não deve ser meramente concebido como a inscrição cultural de significado num sexo previamente dado (Butler, 2003, pp. 24- 25).

Quando se fala de um sujeito em um corpo que se constitui a partir de um contexto social e histórico, não há a pretensão de rejeitar todos os aspectos fisiológicos que compõem este corpo. Todavia, enfatiza-se esse processo como sendo uma construção social e histórica acerca das características atribuídas ao sexo biológico. Desta forma, o conceito de gênero está atrelado a maneira como "as características sexuais são compreendidas e representadas, ou então, como são trazidas para a prática social e tornadas parte do processo histórico" (Louro, 1997, p. 22).

Para Connell (1995, p. 188), “a masculinidade é uma configuração de prática em torno da posição dos homens nas estruturadas relações de gênero". Portanto pensar as formas de ser e existir em sociedade requer compreender o fenômeno que proporciona, regulariza, valida e poda os processos da identidade de gênero. É neste cenário, considerando tanto o biológico como as articulações e desdobramentos que constituem as concepções em relação ao gênero, que podemos pensar acerca de como o processo de construção da identidade de gênero ocorre.

Neste momento, podemos refletir acerca das ferramentas e tecnologias sociais utilizadas para a manutenção dessas concepções. Visto que muitas das características descritas se assemelham em nível semântico de uma forma transversal no tempo, espaço e história. Ao longo das narrativas, essas ferramentas apresentam-se nas relações cotidianas, como forma de subjetivação e produção de verdades em relação tanto à sexualidade, quanto à identidade de gênero.

Postura correta de homem... Pra nós
não ser afeminado... Te agarrar nas
pessoas e rir. (Heitor)

Quando a gente é mais criança, pra mostrar, pra diferenciar da criança que não sabe o que é.... Um carrinho..., tipo um gurizinho... um homem, um gurizinho pega uma boneca, dizer assim, né, que já é para mostrar, né: Olha, isso aqui é de guri e isso daqui é de guria. É, eu faço. $O$ que é de menino eu faço, né. Eu não faço nada que seja do sexo contrário (André).

Fica evidente, as formas como a produção de verdade, em relação ao comportamento e identidade dos sujeitos, vão sendo validadas e articuladas, de forma que o controle sobre os corpos seja exercido, utilizando-se das ferramentas discursivas. Para Foucault (2012), os mecanismos de poder devem ser considerados como técnicas, criadas, aperfeiçoadas, se desenvolvendo sem cessar, existindo uma "tecnologia dos poderes". Para o filósofo, o poder pode ser analisado como "uma malha capilar" de "micropoderes", que sutilmente se espalham através de práticas repetitivas. Este é um poder que está no cotidiano, presente nas mais singelas práticas, não tendo como evitá-lo, sendo exercido sobre o próprio corpo dos indivíduos (Foucault, 
2012). "O micropoder não tem uma ação exclusivamente negativa e proibitiva, mas ele é, principalmente, exercido de uma forma construtiva. Ele produz positivamente comportamentos e corpos através de classificações, normatizações e adestramentos" (Rodrigues, 2003, p. 116).

Segundo Foucault (2002), é no território onde o poder acontece, onde se exerce o controle das subjetividades, nele se instala o olho vigilante do poder disciplinar, que se vende com os modos de ser, formas coletivas de conceber a vida e a existência. A tecnologia da disciplina é o mecanismo de poder que permite o controle social, chegando aos "átomos" sociais, os indivíduos. Foucault (2012, p 177), caracteriza a disciplina:

Técnicas de individualização do poder. Como vigiar alguém, como controlar sua conduta, comportamento, suas atitudes, como intensificar sua performance, multiplicar suas capacidades, como colocá-lo em seu lugar, onde ele será mais útil: a meu ver, eis o que é a disciplina.

Neste sentido, o comportamento social, caracterizado pela masculinidade, é construído no processo de subjetivação na trama social, sendo alvo de vigilância, validação e controle. Oliveira (2004) atenta para a masculinidade como um espaço simbólico, modelador de atitudes, comportamentos e emoções que devem ser seguidos. Desta forma, aos que seguem tais pressupostos, é atribuído o atestado de homem, e não há questionamentos sobre sua identidade por aqueles que compartilham dos mesmos símbolos. Assim, o comportamento é controlado entre os pares, na trama social, no processo de subjetivação e construção da identidade.

Beijar na boca de um guri já é uma coisa, sei lá, isso não se faz. (André)

Quando eu era pequeno eu gostava de brincar de boneca com as minhas colegas da escola...No $2^{\circ}$ ano. Daí os guris ficavam reclamando, falando que isso era coisa de menina. Só que daí eu não revidava.... Que eu ficasse jogando futebol, sendo que eu odeio futebol. (Bernardo).

A análise das relações de poder a partir da perspectiva Foucaultiana permite o rompimento com a polarização entre o masculino e o feminino, visto que impede a aceitação de que apenas um dos dois polos detém o poder, enquanto o outro é totalmente e incontestavelmente submetido a ele. Esse fato não impede, porém, que em determinados momentos - mesmo que na maioria deles alguns dos sujeitos estejam mais submetidos às manobras de poder do que outros. Foucault (1977 apud Cappelle, Melo, Brito \& Brito, 2004) descreve esse efeito disciplinarizante do exercício do poder como a aptidão para docilizar corpos, induzir comportamentos desejados e esvaziar sua capacidade de contestação. Desta forma a regularização ocorre a partir dos micropoderes exercida no território e pelos próprios atores no cenário sociocultural.

\section{A adolescência e o ato infracional sob uma nova perspectiva: reflexões sobre o gênero}

Escolher o recorte deste estudo -dado pela fase do desenvolvimento nomeada como adolescência e o cumprimento de medidas socioeducativas- suscita uma reflexão sobre este fenômeno, sobre como se dá a relação entre esta fase do ciclo vital e o ato infracional. Para tal, é imprescindível que continuemos a seguir a linha traçada, como em um funil, chegar à essa reflexão implica compreender as concepções apresentadas e significadas pelos adolescentes até o momento. Entender o processo de construção da identidade como apresentado na primeira seção, nos possibilita compreender as características elencadas como masculinas na segunda. E este percurso, nos dá pistas preciosas para pensarmos acerca do fenômeno do Ato Infracional.

Segundo o Estatuto da Criança e do Adolescente - ECA (Lei $\left.n^{\circ} 8.069,1990\right)$ a 
adolescência é o período compreendido entre os doze e dezoito anos de idade, no qual este sujeito é concebido como um ser em desenvolvimento, possuidor de todos os direitos inerentes ao ser humano. No entanto, nem sempre esse período existiu da forma como conhecemos na contemporaneidade, sendo construído através de um percurso histórico. No período anterior ao século de XIX, à esta fase da vida não se atribuíam singularidades desenvolvimentais, sendo que a partir da infância se passava diretamente para a vida adulta, sem que houvesse um período de transição (Ferreira \& Nelas, 2006). Na medida em que a sociedade industrial emerge com mais força, se marca o mundo do trabalho como pertencente ao adulto e as escolas como espaços para crianças, seres dependentes de seus pais. Concomitante a isso é que se começa a enxergar a adolescência como um período entre $\mathrm{o}$ adulto e o infantil, permeada por questões individuais, biológicas, sociais e culturais (Salles, 2005).

Atualmente se percebe a adolescência como um momento do desenvolvimento que se inicia depois da infância e se encerra com o ingresso na vida adulta, sendo caracterizada por transformações físicas e psicológicas, as quais acarretam modificações dos padrões infantis até então existentes (Ferreira \& Nelas, 2006). Dentre as diversas modificações desta fase da vida se destaca a sexualidade como aspecto importante e que tem na adolescência um período necessário de vivências para sua consolidação. As mudanças físicas disparam um novo modo de o adolescente olhar para si, de forma que tem sua imagem corporal modificada e, logo, sua identidade (Cano, Ferriani, \& Gomes, 2000). Para isso, o adolescente passa a buscar novas referências além da família, que é a principal referência da infância. Assim novos significados passam a ser construídos através da interação social, que acarreta a identificação com o feminino ou com o masculino e seu sentido no contexto social; permeado de expectativas e normas que orientam o comportamento e atividades destinadas aos homens ou às mulheres (Bordini \& Sperb, 2012). É a partir desse entendimento que se pensa na adolescência como um período no qual se pode identificar as características e sentidos em relação aos gêneros, compreendendo também como "sendo capazes de fazer construções próprias a respeito do masculino e do feminino, os indivíduos contribuem para a elaboração permanente de tais definições e, ao mesmo tempo, para a construção de suas identidades." (Bordini \& Sperb, 2012, p. 739).

Assim, na contemporaneidade, compreender o espaço singular que o adolescente ocupa atravessa diversos cenários. Como no advento da criação do ECA, que postula o termo ato infracional, passando a ser utilizado para descrever condutas caracterizadas como crimes ou contravenções penais cometidas por menores de 18 anos. $\mathrm{O}$ que atende também a exigência constitucional, segundo o artigo 228 da Constituição Federal de 1988 (Constituição da República Federativa do Brasil, 1988), sobre a imputabilidade penal de adolescentes. Neste sentido, fica estabelecido que o adolescente autor de ato infracional será responsabilizado conforme previsto no ECA e não no Código Penal Brasileiro.

É por meio dessa concepção de espaço singular de desenvolvimento ocupado pela adolescência, que vão sendo pensadas novas formas de responsabilização desses sujeitos, visto que o termo penalização é utilizado apenas na esfera criminal - destinada à adultos. Assim, ao cometerem algum ato infracional o adolescente está sujeito ao cumprimento de medidas socioeducativas. Estas, são dispositivos legais criados com finalidade educacional, em que se busca possibilitar ao adolescente em conflito com a lei novas experiências, voltadas à reflexão dos atos e vislumbre de novas possibilidades, para além do ato infracional. A aplicabilidade das medidas abrange adolescentes de 12 a 21 anos de idade (caso o ato tenha sido cometido antes dos 18 anos de idade), conforme previsto no Estatuto da Criança e do Adolescente - ECA (Lei $\mathrm{n}^{\mathbf{0}}$ 8.069, 1990). A partir de suas especificidades jurídicas, a medida aplicada ao adolescente em conflito com a lei pode variar 
conforme a caracterização da infração ou contravenção penal e seus agravos. As medias são normatizadas pelo Sistema Nacional de Atendimento Socioeducativo-SINASE, que reafirma a diretriz do ECA (Lei $\left.{ }^{\circ} 8.069,1990\right)$ sobre a natureza pedagógica da medida socioeducativa e da corresponsabilidade da família, da sociedade e do Estado. As medidas socioeducativas se dividem em: advertência, obrigação de reparar o dano, prestação de serviços à comunidade, liberdade assistida, semiliberdade e internação, sendo as duas últimas medidas restritivas de liberdade, de caráter excepcional e breve, na impossibilidade de aplicação das medidas em meio aberto (SINASE, 2018).

Conforme já citado, cerca de $97 \%$ dos adolescentes em cumprimento de medidas socioeducativas, em meio fechado, no Rio Grande do Sul são do sexo masculino (SINASE, 2018). Característica também evidenciada no âmbito aberto e nacional, cerca de $88 \%$ da população adolescente em cumprimento de medida socioeducativa é do sexo masculino, conforme a Rede SUAS (2018). O que podemos evidenciar a partir dos dados estatísticos é que os principais atos cometidos por adolescentes são: Tráfico de drogas, Roubo e Furto, que juntos constituem cerca de $58 \%$ dos atos infracionais (Rede SUAS, 2018). Para o âmbito fechado as características dos atos com maiores índices são: Roubo (50\%), Homicídio (16\%), Tentativa de Homicídio (10\%) e Tráfico de drogas $(7 \%)$ (SINASE, 2018). Desta forma, os relatórios evidenciam características importantes para compreender o fenômeno da conduta conflitiva com a lei.

Para tanto, é necessário considerarmos, ainda, as variáveis que compõem este cenário, tais como as desigualdades sociais, desemprego, vulnerabilidade, pobreza e raça. Porém, este estudo volta-se para o fenômeno do gênero, portanto, é imprescindível que possamos refletir acerca da ideia de masculino apresentado ao longo deste escrito e os atos infracionais mais cometidos. A caracterização das condutas condenadas pelo Estado se assemelha em algumas instancias com as características comportamentais geradas na trama sociocultural e compreendidas como sendo inerentes do ser homem.

O homem já é mais explosivo. (André)

No estado alcoólico sem pensar no que está fazendo, desrespeitando quase sempre. Não muda nada do estado normal.... às vezes controla. Pode ser um machista, que tem preconceito com as mulheres. (Bernardo)

O sujeito é um dos atores do tripé
entre
cultura/sociedade/história e, o Estado. A cultura produz um discurso sobre a masculinidade que espelha o processo de construção da identidade masculina dos adolescentes aqui entrevistados. E este discurso, justamente, choca-se com o Estado em relação às condutas tidas como violentas, explosivas ao passo que reprime e penaliza as práticas caracterizadas como conflitivas com a lei.

Chimin Junior (2009) aponta para a importância de se considerar o contexto socioespacial como um importante fator da vulnerabilidade de adolescentes do sexo masculino em relação aos atos infracionais. Tendo em vista a fase de desenvolvimento que este sujeito vivencia, as experiencias, relações e significados corroboram nas condutas que vão ser identificadas como pertencentes à sua identidade. Assim, em contextos violentos, o adolescente pode simultaneamente ocupar o lugar de vítima, como também, de promotor de violência (Chimin Junior, 2009).

Ao compreendermos que o processo de construção da identidade se dá nas experiencias cotidianas, implicadas na relação com o outro, podemos refletir acerca de como a cultura e sociedade produzem as formas de ser e existir em determinados contextos. As relações de gênero se dão de forma performática, conforme Butler (2003) citada por Chimin Júnior (2009, p.46) não há gênero pré-existente, este deve ser "compreendido como instável, constituindo-se 
paulatinamente no tempo e em um espaço externo através da repetição estilizada de determinados atos". Nesse sentido, compreender as condutas conflitivas dos adolescentes relacionados ao seu processo de identificação, implica, necessariamente, em compreender as espacialidades vivenciadas no cotidianamente (Chimin Junior, 2009), visto que é neste que as relações e significações vão se construir, acarretando a ideia de pertencimento e identidade.

Portanto, fica evidente o quanto o processo de construção da identidade masculina e as relações de gênero, apresentamse como um importante marcador para pensarmos a problemática do ato infracional. $\mathrm{O}$ que suscita reflexões acerta das formas como se constrói subjetividade nesta trama sociocultural. Assim, ao considerarmos os demais fatores implicados nesta realidade, como as vulnerabilidades sociais, pobreza, desemprego e falta de acesso à saúde e educação, estes não devem sobrepor a discussão acerca dos papéis gênero e a performatividade que compõem este fenômeno, mas sim englobá-lo nas estratégias de socioeducação.

\section{Considerações finais}

O objetivo deste estudo buscou elucidar as concepções de adolescentes, em cumprimento de medidas socioeducativas, acerca da masculinidade; visando desta forma, compreender os processos de construção da identidade masculina. É a partir da análise das narrativas que pudemos sublinhar os sentidos atribuídos ao ser homem para os participantes deste estudo.

Foi possível identificar as concepções e significações dos adolescentes acerca da sua identidade, evidenciando o fenômeno de identificação e a sua importante relação com o Outro. De forma que, para construir sua identidade o sujeito necessita tanto do pertencimento, quanto da diferenciação, seja de características físicas ou comportamentais, visíveis e invisíveis, individuais e coletivas. Concepção evidenciada através da identificação binária. Visto que os adolescentes construíram suas narrativas através da diferenciação em relação ao feminino. Um não é o outro pelo critério da exclusão.

Assim como a literatura nos conta, o processo de diferenciação se iniciou a partir das diferenças visíveis, biológicas e estruturais do humano, dando sequência às práticas sociais, como o comportamento. Apesar da amostra pequena, as entrevistas possibilitaram perceber um esforço em relação à diferenciação do feminino. Aqui o discurso deixa de ser voltado ao determinismo biológico e passa a ser voltado à conotação de obrigatoriedade de não se portar como mulher. Assim, ser homem é não ser mulher e não agir como uma. Ademais, é a partir das normativas e reconhecimento da identidade, que pudemos perceber, ainda, como é exercido o controle sobre as maneiras de ser e existir em relação à masculinidade. Construídas e validadas na trama social, as relações de gênero vão subjetivando os sujeitos e construindo formas aceitáveis e refutáveis de ser na masculinidade. Assim, o controle é exercido na trama social, no território, no tempo e espaço compartilhado pelos indivíduos.

Todo este delinear nos possibilitou pensar acerca do fenômeno do ato infracional, visto que a amostragem deste estudo (adolescentes do sexo masculino) foi eleita por seu protagonismo em relação aos atos infracionais, ou seja, embora os falas corroborem com o apresentado pela literatura, e talvez pudessem ser ditas por muitos adolescentes do sexo masculino, elas vieram de um recorte bastante específico e que não foi escolhido ao acaso, uma vez que problematizar os altos índices de meninos em conflito com a lei, requer um olhar acerca, principalmente, do processo de construção da identidade desses adolescentes; visto que as atitudes, escolhas, experiencias, e formas de ser estão diretamente ligadas a performance em relação ao processo de identificação. Desta forma, perceber as características atribuídas ao masculino colocanos mais perto das práticas compreendidas como corretas ou não-inadequadas. 
Posto isso, este estudo não buscou traçar uma relação de causa e efeito, nem de eximir o adolescente de seus atos, mas sim possibilitar novos olhares acerca da problemática multifatorial da conflitiva com a lei, tomando como cerne da discussão o processo de construção da identidade de gênero. Fator que possui relevância, tanto nas narrativas, quanto nas estatísticas acerca deste fenômeno.

\section{Referências}

Betim, D., \& Lurke, B. O. (2019). Atos de fala sobre gênero e sexualidade: a necessidade do contradiscurso. Revista X, 14(4), 222239. doi: $10.5380 /$ rvx.v14i4.66127

Bordini, G. S., \& Sperb, T. M. (2012). Concepções de gênero nas narrativas de adolescentes. Psicologia: Reflexão e Crítica, 25(4), 738-746. doi: 10.1590/S0102-79722012000400013

Boris, G. D. J. B., Bloc, L. G., \& Teófilo, M. C. C. (2012). Os rituais da construção da subjetividade masculina. $O$ público e $O$ privado, 19, 17-32. Recuperado de http://www.seer.uece.br/?journal=opublicoe oprivado\&page $=$ article \&op $=$ view \&path $\% 5$ $\mathrm{B} \% 5 \mathrm{D}=334$

Brasil. (2018). Levantamento anual SINASE 2016. Brasília: Ministério dos Direitos Humanos. Recuperado de http://www.mdh.gov.br/assuntos/criancase-adolescentes/programas/sistemanacional-de-medidassocioeducativas/Levantamento_2016.pdf

Butler, J. (2003). Problemas de gênero: feminismo e subversão da identidade. Rio de janeiro: Editora Record.

Cano, M. A. T., Ferriani, M. G. C., \& Gomes, R. (2000) Sexualidade na adolescência: um estudo bibliográfico. Revista LatinoAmericana de Enfermagem, 8(2), 18-24. Recuperado de http://www.scielo.br/pdf/rlae/v8n2/12413

Cappelle, M. C. A., Melo, M. C. O. L., Brito, M. J. M., \& Brito, M. J. (2004). Uma análise da dinâmica do poder e das relações de gênero no espaço organizacional. $R A E$ eletrônica, 3(2), 1-17. Recuperado de http://www.scielo.br/scielo.php?script=sci arttext\&pid=S1676-56482004000200006

Chimin Junior, A. B. (2009). O espaço como componente da vulnerabilidade dos adolescentes do sexo masculino e em conflito com a lei para a conduta infracional.Terr@Plural,3(1),41-53. Recuperado de http://www.revistas2.uepg.br/index.php/tp/ article/view/1191

Connell, R. W. (1995) Políticas da masculinidade. Educação \& Realidade. 20(2), 185-206. Recuperado de https://seer.ufrgs.br/index.php/educacaoere alidade/article/view/71725

Connell, R.W., \& Messerschmidt, J. W (2013). Masculinidade hegemônica: repensando o conceito. Revista Estudos Feministas, 21(1), 241-282. Recuperado de https://periodicos.ufsc.br/index.php/ref/artic le/view/S0104-026X2013000100014

Constituição da República Federativa do Brasil de 1988. Recuperado de http://www.planalto.gov.br/ccivil_03/Const ituicao/Constituicao.htm

Deleuze, G. (2013). Conversações: 19721990. São Paulo: Ed. 34.

Domingues, C. M. A. S., \& Alvarenga, A. T. (1997) Identidade e sexualidade no discurso adolescente. Revista Brasileira de Crescimento e Desenvolvimento Humano, 7(2), 36-63. Recuperado de https://www.revistas.uspp.br/jhgd/article/vi ew/38564/41410

Fundação de Atendimento Socioeducativo do Rio Grande do Sul [FASE]. (2018). Histórico institucional. Recuperado de http://www.fase.rs.gov.br/wp/institucional/ historico/

Ferreira, M., \& Nelas, P. B. (2006). Adolescências... Adolescentes... Revista Millenium - Educação, Ciência e Tecnologia, 32, 141-162. Recuperado de http://revistas.rcaapp.pt/millenium/article/vi ew/8399/5990 
Foucault, M. (2002). Problematização do Sujeito: Psicologia, Psiquiatria e Psicanálise (Ditos e Escritos). Rio de Janeiro: Forense Universitária.

Foucalt, M. (2012). Segurança, Penalidade e Prisão (Ditos e Escritos v.8). Rio de Janeiro: Forense Universitária.

Lei $n^{o}$ 8.069, de 13 de julho de 1990. Dispõe sobre o Estatuto da Criança e do Adolescente e dá outras providências. Recuperado de http://www.planalto.gov.br/ccivil 03/leis/18 069.htm

Louro, G. L. (1997). Gênero, sexualidade e educação: uma perspectiva pós estruturalista (6 $6^{\mathrm{a}}$ ed.). Petrópolis: Vozes.

Martins, A. P. V. (2004). Visões do feminino: a medicina da mulher nos séculos XIX e $X X$. Rio de Janeiro: Editora FIOCRUZ. Recuperado de http://books.scielo.org/id/jnzhd/pdf/martins -9788575414514.pdf

Melo, M. L. A. (2016). Contribuições da hermenêutica de Paul Ricoeur à pesquisa fenomenológica em psicologia. Psicologia USP, 27(2), 296-306.

Oliveira, P. P. (2004). A construção social da masculinidade. Belo Horizonte: Editora UFMG.

Pongeluppe, M. A. B., \& Milani, D. R. C. (2017). A masculinidade hegemônica advinda dos enredos midiáticos - um jeito de ser masculino. Revista Brasileira de Sexualidade Humana, 28(2), 08-16. doi: 10.35919/rbsh.v28i2.17

Rede SUAS. (2018). Pesquisa Nacional das Medidas Socioeducativas em Meio Aberto 2018. Recuperado de http://blog.mds.gov.br/redesuas/pesquisa$\underline{\mathrm{mse}}$

Rodrigues, S. M. (2003). A relação entre o corpo e o poder em Michel Foucault. Psicologia em Revista, 9(13), 109-124. Recuperado de http://periodicos.pucminas.br/index.php/psi cologiaemrevista/article/view/168/181

Salles, L. M. F. (2005). Infância e adolescência na sociedade contemporânea: alguns apontamentos. Estudos de Psicologia (Campinas), 22(1), 33-41.
Recuperado de http://www.scielo.br/scielo.php?script=sci arttext\&pid=S0103$166 \times 2005000100005 \& \operatorname{lng}=$ en $\& n r m=$ iso

Silva, R. S., \& Silva, Q. S. (2016). Sexo, gênero e poder: um olhar sobre o processo de construção das identidades no cotidiano escolar. Seminário Nacional: Demandas Sociais e Políticas Públicas na Sociedade Contemporânea, Santa Cruz do Sul, RS, Brasil, 12. Recuperado de http://online.unisc.br/acadnet/anais/index.p hp/snpp/article/view/14589/3339

Silva, H. A. (2010). Abordagem fenomenológica-hermenêuticas. ÁgoraRevista Eletrônica, 54-58. Recuperado de http://agora.ceedo.com.br/agora10/abordag emfenomenologica_hermeneutica_Henriqu etaAlvesdaSilva.pdf.

Silva, S. G. (2000) Masculinidade na história: a construção cultural da diferença entre os sexos. Psicologia: Ciência e profissão, 20(3), 8-15. Recuperado de http://www.scielo.br/scielo.php?pid=S1414

98932000000300003\&script=sci_arttext\&tl ng=es

Silva, T. T. (2012) A produção social da identidade e da diferença. In T. T.0 Silva (Org.), Identidade e diferença: a perspectiva dos estudos culturais (pp. 73102). Petrópolis, RJ: Vozes.

Spink, M. J. (2010) Linguagem e produção de sentidos no cotidiano [online]. Rio de Janeiro: Centro Edelstein de Pesquisas Sociais. Recuperado de http://books.scielo.org/id/w9q43/pdf/spink9788579820465.pdf

Souza, E. R. (2005). Masculinidade e violência no Brasil: contribuições para a reflexão no campo da saúde. Ciência \& Saúde Coletiva, 10(1), 59-70. Recuperado de

http://www.scielo.br/scielo.php?script=sci abstract\&pid=S1413$\underline{81232005000100012 \& \operatorname{lng}=e \& t \operatorname{lng}=p t}$

Vasconcelos, A. C de S., Monteiro, R. J. S., Facundes, V. L. D., Trajano, M. de F. C. \& Gontijo, D. T. (2016). Eu virei homem!: a construção das masculinidades para 
adolescentes participantes de um projeto de promoção de saúde sexual e reprodutiva.

Saúde e Sociedade, 25(1), 186-197.

Recuperado de

http://www.scielo.br/scielo.php?script=sci_artt

ext\&pid=S0104-

$\underline{12902016000100186 \& l a n g=p t}$

Woodward, K. (2012). Identidade e diferença: uma introdução teórica e conceitual. In T.
T. Silva (Org.), Identidade e diferença: $a$ perspectiva dos estudos culturais (pp. 772). Petrópolis, RJ: Vozes.

Zambrano, E., \& Heilborn, M. L. (2012). Identidade de gênero. In A. C. S. Lima (Org.). Antropologia \& direito: temas antropológicos para estudos jurídicos (pp. 412-418). Rio de Janeiro: ABA.

\section{Dados sobre as autoras:}

- Marcia de Bastos Braatz: Psicóloga. Graduada pela Universidade de Santa Cruz do SulUNISC.

- Gabrielly da Fontoura Winter: Doutoranda em Psicologia Social e Institucional pelo Programa de Pós-Graduação da Universidade Federal do Rio Grande do Sul. Mestre em Educação pelo Programa de Pós-graduação em Educação da Universidade de Santa Cruz do Sul (UNISC 2016). Graduada em Psicologia pela Universidade de Santa Cruz do Sul (UNISC - 2013). Professora do departamento de ciências da Saúde da Universidade de Santa Cruz do Sul. Coordenadora do curso de Psicologia da Universidade de Santa Cruz do Sul- campus Montenegro/Rs. Integrante do Núcleo de Estudos em Políticas Contemporâneas de Subjetivação (e-politics) coordenado pela Dra. Neuza Maria de Fátima Guareschi. Atua como pesquisadora voluntária no projeto de pesquisa: Inclusão e mídia. coordenado pela Dra.Betina Hillesheim.

A submissão de originais para este periódico implica na transferência, pelos autores, dos direitos de publicação impressa e digital. Os direitos autorais para os artigos publicados são do autor, com direitos do periódico sobre a primeira publicação. Os autores somente poderão utilizar os mesmos resultados em outras publicações indicando claramente este periódico como o meio da publicação original. Em virtude de sermos um periódico de acesso aberto, permite-se o uso gratuito dos artigos em aplicações educacionais e científicas desde que citada a fonte conforme a licença CC-BY da Creative Commons. 